\title{
Are we at a turning point in journal assessment? An introduction to altmetrics
}

\author{
Erwin Krauskopf*
}

\begin{abstract}
The status of any journal in which research is published is an important issue for academics. For many years the impact factor has been the criteria of choice to infer the quality of the research being published by each journal. However, with the massification of the internet, research currently impacts well beyond the academic community. This study aims to introduce readers into other bibliometric and non-bibliometric (altmetric) indicators that provide a wider perspective about the impact any particular research outcome may have besides citations. From a geographic viewpoint, the documents published by AJVS between 2010-2019 were written by authors affiliated to institutions from 33 different countries, mostly from Chile (37\%) and Mexico (24\%). These two countries served as collaboration nodes for countries from America, Asia, Europe and Oceania. From an altmetric perspective, 59 documents published between 2010-2016 were mentioned at least once in one of the sources tracked, being the majority of them through social media. Of particular interest is one document that was used as a reference for a patent issued in 2017 by researchers that were not related to the document published in the journal. Unfortunately, data for the documents published between 2017-2019 were unavailable, probably due to issues with the journal title change. Nevertheless, it is fair to conclude that since research outputs have shown to have an impact well beyond academia, it may be time to reconsider how journals should be assessed in the near future.

Key words: altmetrics, bibliometric, assessment.
\end{abstract}

\section{INTRODUCTION}

A past editorial of the Austral Journal of Veterinary Sciences (Anonymous 2019) introduced readers into the world of journal metrics based on the use of the journal impact factor to assess the quality of any given journal. Although many studies have expressed concerns with the misuse of the journal impact factor (JIF) (Colquhoun 2003, McKiernan et al 2019, Pang 2019), it is still used regularly to evaluate individual researchers, departments and institutions (Pan and Fortunato 2014). In Chile, the use of this indicator has even extended to the assessment of research proposals granted by the National Fund for Scientific and Technological Development (known as Fondecyt) in study areas such as "animal health and production"1.

Opportunely, many members of the research community have considered alternative metrics to evaluate journals where to submit their manuscripts, following the guidelines set six years ago at the San Francisco Declaration on Research Assessment, also known as DORA (Pulverer 2013). This manifesto states that while the use of the impact factor as a promotional tool should be reduced, other journal metrics should be highlighted (such as editorial and publication times and h-index). One of the

Received: 26.03.2020.

Accepted: 24.07.2020.

Facultad Ciencias de la Vida, Universidad Andrés Bello, Santiago, Chile.

*Corresponding author: E Krauskopf; Facultad Ciencias de la Vida, Universidad Andrés Bello, Santiago, Chile; Edificio C1 Primer Piso, Fernández Concha 0700, Las Condes, Santiago, Chile; erwin.krauskopf@unab.cl

1 CONICYT. 2019. Bases Concurso Nacional de Proyectos Fondecyt Regular 2020. http://www.conicyt.cl/fondecyt/files/2019/05/ Bases-Concurso-FONDECYT-Regular-2020.pdf; accessed January 2020. main issues about the impact factor is the fact that it can be influenced and biased. To estimate the impact factor for any given journal, the formula considers total citations received by all document types published during the two previous years, divided by the total number of articles and reviews published over the same two years. However, since citations are counted for document types not considered in the denominator (known as the numerator/denominator asymmetry), the impact factor is artificially inflated ${ }^{2}$. Furthermore, publishing a larger amount of reviews instead of other types of documents usually provides more citations to the journal. Other known strategies used to increase the citation rate of a journal consist of providing early access online to accepted manuscripts or by increasing its publication frequency. But in the end, the purpose of all high-quality journals should be the dissemination of new research findings to the precise audience, which is not only circumscribed to the academic world. In fact, the outcome of many published studies has benefited society or the environment as supporting evidence for clinical practice guidelines, systematic review and meta-analysis (including network meta-analysis) and also through the generation of public policies, patents, etc. For instance, the policy document "Salmonella in livestock production in Great Britain", issued by the UK government in 2016, was based on 26 documents that were published by different journals among which were Avian Pathology, Veterinarian Microbiology and Preventive Veterinary Medicine. Likewise, many documents published on scholarly veterinary journals have been used as reference

2 Lariviere V, Sugimoto CR. 2018. The journal impact factor: A brief history, critique and discussion of adverse effects. In: Springer handbook of science and technology indicators, Pp 1-33. https:// arxiv.org/1801.08992.pdf; accessed January 2020. 
for patents. As an example, an article that characterised proteases involved in egg hatching of the sheep blowfly (Young et al 2000) was used to generate a patent entitled "Methods and compositions for controlling ectoparasites" in 2012 (Application EP-2457582-A1).

Indeed, the massification of the Internet in the 1990s generated the possibility of evaluating the visibility of academic publications through new indicators, known as alternative bibliometric indicators (or altmetrics) (Priem et al 2012). These indicators certainly complement the information provided by traditional bibliometric indicators, allowing a more global assessment of the impact of scientific publications generated as a product of research projects. The main advantage of alternative bibliometric indicators is that these provide information at the article level, allowing their assessment well beyond academia, considering social, cultural, environmental, and economic returns of the research output (Anonymous 2018). Likewise, these indicators reflect in real-time if the article is discussed in social networks or other platforms (Zahedi et al 2014). One of the tools used to study these indicators is Altmetric explorer, which provides an Altmetric Attention Score (AAS) for all documents that have been mentioned at least once on the data sources tracked (table 1). The final score is derived from an algorithm that represents a weighted count of the amount of attention received by a specific research output ${ }^{3}$.
Concomitantly, the purpose of this study was to assess the performance of the Austral Journal of Veterinary Sciences between 2010 and 2019, through the use of different bibliometric strategies, providing a journal assessment that moves away from the traditional impact factor.

\section{MATERIAL AND METHODS}

Bibliometric information was retrieved from Web of Science on the week of January 21, 2020 for the journal Austral Journal of Veterinary Sciences (and its previous title Archivos de Medicina Veterinaria) for the period 2010-2019. The downloaded data was sorted and processed using Microsoft Excel and SequelPro. The bibliometric map was built using the VOSviewer software (van Eck and Waltman 2010) based on the Web of Science downloaded data. To build the collaboration network, the information provided in affiliation records of each publication was utilised to extract the countries of co-authors.

Non-bibliometric information was retrieved using Altmetric Explorer ${ }^{4}$ as the search engine because it captures real-time mentions in public policy documents, mainstream media, online reference managers, peer-review platforms and blogs (Altmetrics 2019, Hassona et al 2019). The query was made on January 22, 2020 for documents that were published by the journal titles

Table 1. Sources currently tracked by Altmetrics for mentions of research outputs* (Altmetrics 2020).

\begin{tabular}{lcl}
\hline \multicolumn{1}{c}{ Source name } & Weight & \multicolumn{1}{c}{ Notes } \\
\hline News & 8 & $\begin{array}{l}\text { Manually curated news sources, with data provided via a third-party provider and RSS } \\
\text { feeds direct. }\end{array}$ \\
Blogs & 5 & $\begin{array}{l}\text { Manually curated list, harvesting links to scholarly content. } \\
\text { Policy documents }\end{array}$ \\
Wikipedia & 3 & $\begin{array}{l}\text { Scanning and text-mining policy document PDFs for references, which are looked up in } \\
\text { CrossRef/PubMed and resolved to DOIs. }\end{array}$ \\
Patent Citations & 3 & Mentions of scholarly outputs collected from References section. English Wikipedia only. \\
Twitter & 1 & Demographics, support for retweets, with monitoring of suspicious activity. \\
Post-publication peer reviews & 1 & Peer review comments collected from item records and associated by unique identifier. \\
F1000Prime recommendations & 1 & Scan for links to scholarly outputs. \\
Open Syllabus & 1 & Link syllabi's contents to HLOM IDs. \\
Facebook & 0.25 & Posts on public Facebook Pages only, with prioritised popular Pages. \\
Reddit & 0.25 & Includes all sub-reddits. Original posts only, no comments. \\
Q\&A (Stack Overflow) & 0.25 & Scan for links to scholarly outputs. \\
YouTube & 0.25 & Scan for links to scholarly outputs in video descriptions. \\
Mendeley & 0 & Reader counts is number of readers with the output in their Library. \\
Web of Science Citations & 0 & Citation counts from peer-reviewed literature. \\
Dimensions Citations & 0 & Match outputs based on scholarly IDs. \\
\hline
\end{tabular}

* Altmetrics. 2020. What outputs and sources does Altmetric track? https://help.altmetric.com/support/solutions/articles/6000060968-what-outputsand-sources-does-altmetric-track-; accessed June 222020.

3 Altmetrics. 2019. Standards in Altmetrics. https://www.altmetric. com/about-altmetrics/standards-in-altmetrics/; accessed January 28 , 2020.

4 http://www.altmetric.com 
"Archivos de Medicina Veterinaria" or "Austral Journal of Veterinary Sciences". It should be noted that Altmetric began collecting data in 2011.

\section{RESULTS}

A total of 440 documents were published by AJVS during the 10-years period, receiving 981 citations at the time the data was collected. While the majority of these documents were "article"-type documents (387 in total), the mean number of citations per review (26 in total) exceeded that of articles (5.6 vs 2.1 citations per document, respectively). Since the formulas to calculate the JIF and the Scimago Journal Rank (SJR) consider the total amount of citations as well as document types, this information is relevant for the editorial team while assessing journal performance. However, citations statistics only provide a rough measure of research impact.

An analysis of the geographic representation of the documents published by AJVS revealed that the authors were affiliated to institutions from 33 different countries. While Chilean authors have led in terms of contributions (37.0\%) to the journal, the number of documents published annually has decreased over the years (figure 1). Interestingly, AJVS has been continuously used by Mexican researchers to publish their studies. In fact, only two out of the 106 documents published by Mexican researchers were in collaboration with Chilean institutions.

But how do researchers from these countries interact? As figure 2 depicts, Mexico has served as a node for studies in collaboration with countries such as the United States, England, Canada, Nigeria and Iran. Likewise, Chile is a junction in terms of collaboration with researchers from Europe, Oceania and America. A closer look at the affiliations registered by the authors of these documents revealed that the top five institutional contributors were Universidad Austral de Chile (Chile), followed by Universidad de Chile (Chile), Universidad de Caldas (Colombia), Universidad Nacional Autónoma de México (Mexico) and Universidad Autónoma de Baja California (Mexico). This information is relevant to readers as it confirms the international visibility achieved by the journal in the last 10 years.

A systematic search conducted on Altmetric Explorer for documents published by AJVS during the 10-years period revealed a total of 59 documents. The best scoring article (table 2) discussed the methods by which swine are slaughtered commercially from an animal welfare perspective. The breakdown of the AAS showed that $34 \%$ of the people that mentioned this article on Twitter were from Spain, followed by members of the public from Mexico (4\%) and Argentina (3\%). Furthermore, this article was bookmarked by 7 Mendeley readers and cited once by an article published in 2019 by the journal Meat Science. It has been suggested that Mendeley reader counts could be used to assess the future impact of a specific article since these accumulate earlier than citations (Maflahi and Thelwall, 2018). As shown in table 2, other documents published by AJVS additionally received Facebook mentions, which consist of Facebook shares, likes and comments on public Facebook pages that reflect the interactions users may have with a particular research.

In this context, the document entitled "Conductas no deseadas en equinos" published in 2010 is a good example of the impact a research output may have outside the academic community. Five years after the document was published by AJVS, the Venezuelan Veterinary Services of Integral Livestock posted on Facebook a link to the published document. One year later, a private

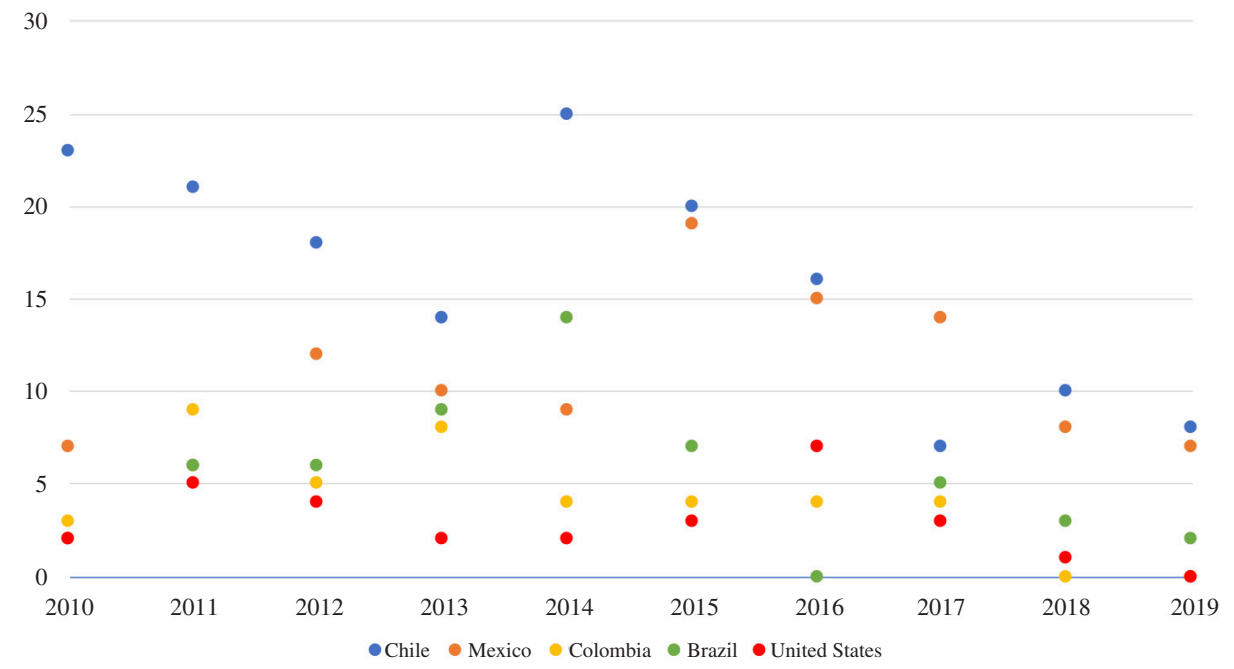

Figure 1. Total amount of documents published between 2010-2019 by researchers from the top-five most prolific countries. 


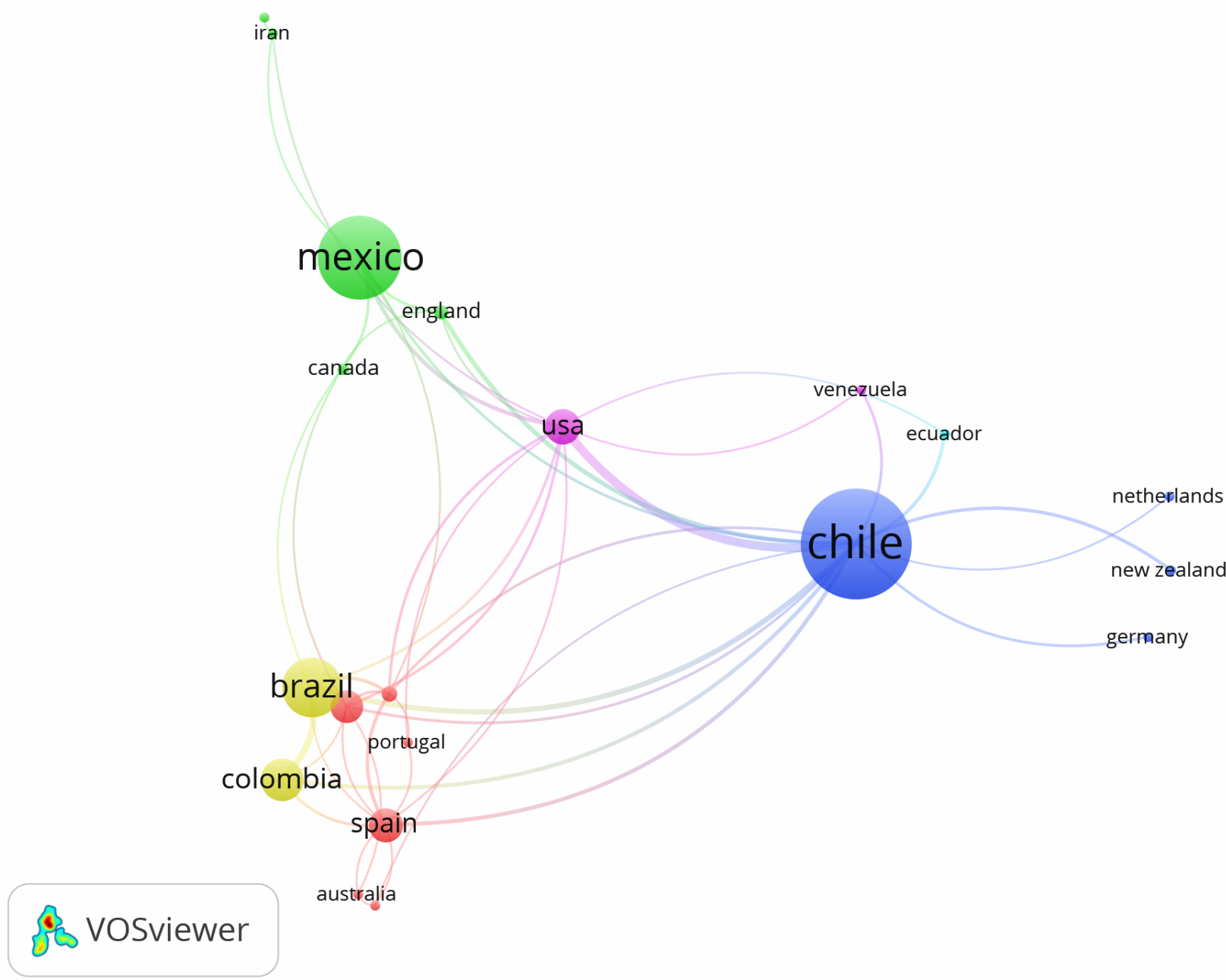

Figure 2. Collaboration network map. The size of the node (circle) represents the number of documents published by authors from that country. A line between two country nodes indicates that researchers from these countries published a document together. The thickness of the line represents the number of collaborations between two nodes.

pay-per-view TV channel from Colombia (TVAgro) posted on its YouTube channel ${ }^{5}$ a video about the inappropriate behaviour observed during the treatment of horses which mentioned the AJVS study.

Another important aspect about altmetrics is that it tracks patent citations from the following jurisdictions: World Intellectual Property Organization, IP Australia, German Patent and Trademark Office, Swiss Federal Institute of Intellectual Property, European Patent Office, United States Patent and Trademark Office, French National Industrial Property Institute, Intellectual Property Office of the United Kingdom and the Netherlands Patent Office. From this perspective, one document published by AJVS was used as a reference for a patent even though it has only been cited three times since its publication in 2015 . The document entitled "Distribution, epidemiological

5 https://www.youtube.com/watch?v=grXNOTJQmz4 characteristics and control methods of the pathogen Nosema ceranae Fries in honey bees Apis mellifera L. (Hymenoptera, Apidae)" served as a reference for a patent granted in Chile entitled "Composition, method and use for controlling fungal infection caused by Nosema ceranae fungus in Apis mellifera bee colonies, comprising application, as a syrup (pj-cd14) and aerosol (pa-cd14), of an effective quantity of essential oil (cd14) obtained from Cryptocaria alba (peumo) leaves" (application WO-2017091915-A1). It is interesting to note that while this patent was filed by researchers from Universidad de Chile, the document published by AJVS was written by researchers from Universidad Católica de Temuco and the Agriculture and Livestock Service (SAG) from Chile. It seems that Chilean researchers are not imbued with the idea of needing to protect their discoveries even though a significant proportion of the new knowledge produced has commercial value (Krauskopf et al 2007, Sargent and Matthews 2014). 
Table 2. Top-10 research output ordered according to their Altmetric Attention Score (AAS).

\begin{tabular}{|c|c|c|c|c|c|c|c|}
\hline Rank & Title & Year & AAS & $\begin{array}{l}\text { \# Tweeter } \\
\text { mentions }\end{array}$ & $\begin{array}{l}\text { \# Mendeley } \\
\text { readers }\end{array}$ & $\begin{array}{l}\text { \# Facebook } \\
\text { mentions }\end{array}$ & $\begin{array}{l}\text { WoS } \\
\text { citations }\end{array}$ \\
\hline 1 & $\begin{array}{l}\text { Evaluación de la eficacia del método de } \\
\text { insensibilización por electronarcosis en } \\
\text { porcinos }\end{array}$ & 2014 & 78 & 92 & 7 & 0 & 1 \\
\hline 2 & $\begin{array}{l}\text { Indicadores de bienestar animal para } \\
\text { detectar problemas en el cajón de } \\
\text { insensibilización de bovinos }\end{array}$ & 2012 & 27 & 32 & 25 & 1 & 12 \\
\hline 3 & $\begin{array}{l}\text { Evaluación de la oferta de pradera y tipo } \\
\text { de concentrado sobre algunos parámetros } \\
\text { ruminales en vacas lecheras en pastoreo } \\
\text { otoñal }\end{array}$ & 2012 & 27 & 31 & 1 & 1 & 6 \\
\hline 4 & $\begin{array}{l}\text { Use of chitosan and polypropylene for the } \\
\text { surgical correction of penile deviation in } \\
\text { bulls: clinical and histological aspects }\end{array}$ & 2012 & 21 & 24 & 1 & 4 & 0 \\
\hline 5 & $\begin{array}{l}\text { Presencia del síndrome de úlcera gástrica } \\
\text { en equinos de la policía militar }\end{array}$ & 2012 & 16 & 18 & 17 & 1 & 4 \\
\hline 6 & $\begin{array}{l}\text { Factores genéticos que inciden en la } \\
\text { resistencia a enfermedades infecciosas en } \\
\text { salmónidos y su aplicación en programas } \\
\text { de mejoramiento }\end{array}$ & 2010 & 7 & 0 & 25 & 0 & 24 \\
\hline 7 & Conductas no deseadas en equinos & 2010 & 5 & 5 & 67 & 1 & 6 \\
\hline 8 & $\begin{array}{l}\text { Distribution, epidemiological } \\
\text { characteristics and control methods of the } \\
\text { pathogen Nosema ceranae Fries in honey } \\
\text { bees Apis mellifera L. (Hymenoptera, } \\
\text { Apidae) }\end{array}$ & 2015 & 3 & 0 & 23 & 0 & 3 \\
\hline 9 & $\begin{array}{l}\text { Effect of the application of stem cells for } \\
\text { tendon injuries in sporting horses }\end{array}$ & 2012 & 3 & 0 & 12 & 0 & 1 \\
\hline 10 & $\begin{array}{l}\text { Primer reporte en Chile de Chrysomya } \\
\text { albiceps (Diptera: Calliphoridae) en } \\
\text { evidencia entomológica forense }\end{array}$ & 2013 & 2 & 1 & 33 & 3 & 3 \\
\hline
\end{tabular}

WoS: Web of Science.

\section{DISCUSSION}

Since 1969, AJVS (formerly known as Archivos de Medicina Veterinaria) has been published uninterruptedly. This timeliness, as well as its editorial content and the application of a peer-review process to select manuscripts, made the journal eligible to be indexed by databases such as Scopus (owned by Elsevier) and Web of Science (owned by Clarivate Analytics). Undoubtedly, the inclusion of any journal into these databases increases exponentially the citation rate of the authors (Krauskopf 2018). Furthermore, it fosters collaboration by displaying the expertise of researchers and the quality of their studies.

For journals that are editorially managed by universities, it is important to avoid publishing more than $20 \%$ of manuscripts authored by researchers from the same home institution (Fuentes et al 2013). Since most local and global rankings consider institutional research output, it seems logical that universities would benefit from publishing documents authored by their own researchers. A recent study determined that out of 22 Chilean journals managed by universities, 11 surpassed the $20 \%$ threshold, among them AJVS with 22.3\% (Krauskopf 2020). Going into more detail, from the 85 documents that included at least one author from Universidad Austral de Chile, 42 were authored exclusively by researchers from Universidad Austral de Chile, 20 were the product of a collaboration between researchers from Universidad Austral de Chile and one or more Chilean institutions, and 23 included researchers from international institutions in collaboration with researchers from Universidad Austral de Chile and other national institutions. It is important to consider that publishing over the $20 \%$ threshold could limit the scope of intellectual coverage, reducing the geographical reach of the journal (Krauskopf 2020).

One of the unexpected results of this study was that contributions from Anglophone countries have not increased even though AJVS modified the language of publication and its name at the end of 2016, turning it into a completely English-language journal. Moreover, 
the proportion of manuscripts authored by researchers from anglophone countries was $8.1 \%$ between 1994-2013, a time at which the proportion of English documents published by AJVS was $14.0 \%$ (Krauskopf et al 2017). It is important to bear in mind that AJVS is currently competing with 141 veterinary journals, according to the Journal Citations Report 2018, most of which publish in English. Thus, the problem might be that researchers from anglophone countries may not be aware of AJVS. Since we are in the era of digital sources, many researchers rely on online keyword searchers such as Google Scholar or by performing queries in social networks such as twitter. A study from 2016 that analysed twitter activities from undergraduate students and academics revealed very interesting results, such as that $73.6 \%$ of academics used twitter to search for information, $88.5 \%$ to share information, and $65.4 \%$ for academic reasons (Knight and Kaye 2016). In the case of undergraduate students, $65.7 \%$ used it to seek information and $27.7 \%$ for academic reasons. Although this study was limited to one institution from the United Kingdom, it shows how digital sources are playing a fundamental role in academic activities. Perhaps the time has come for AJVS to incorporate social networks as part of a digital strategy to create awareness about its contents to the world. Indeed, such an action would bring an increase in AAS.

With regard to alternative indicators, this study established that only $13.4 \%$ of the documents published by AJVS were picked up by Altmetrics. It is important to note that Altmetrics tracks mention of research outputs through the Digital Object Identifier (DOI) associated to each document. Regrettably, according to data extracted from the Web of Science, a total of 120 documents published by AJVS between 2010-2019 lack a DOI (figure 3). Other reasons why Altmetrics may have failed tracking more documents from AJVS might be more of a technical nature. For instance, since the Altmetrics text mining system requires access to data, the blogs need to include a research output identifier to detect a document. In the

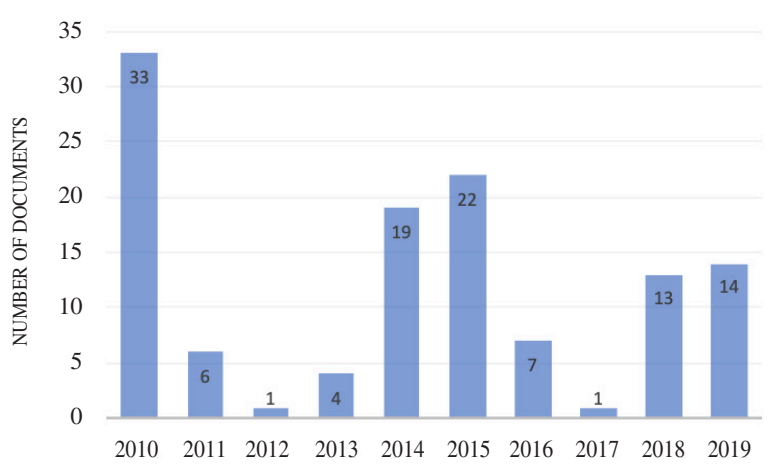

Figure 3. Number of documents published lacking a DOI (Digital Object Identifier). case of social media, an important issue is that Altmetrics only tracks public Facebook and Twitter accounts, simply due to access restrictions.

It is important to note that there are some limitations to this study. First, concerns have been raised about the manipulation of Altmetrics. While this issue is of the essence, it is important to emphasise that this weakness is also seen on other scholarly metrics that are commonly used to assess research impact (Bartneck and Kokkelmans 2010, Krauskopf 2013, Delgado Lopez-Cozar et al 2014). Second, Altmetrics may be misinterpreted as no qualitative assessment of the Altmetric score is made. Mentions of a specific research on Twitter and Facebook may be positive, neutral or negative, just as it occurs with positive and negative citations. (Catalini et al 2015, Bai et al 2017). For instance, an article exhibiting a high AAS might be receiving a lot of online attention because the research presented is questionable. Lastly, as Altmetrics still remains at an ongoing state of development, the lack of benchmarks hinders AAS interpretation. In this context, Thelwall (2017) has proposed a strategy to estimate a set of field normalised alternative indicators. Currently, some research groups are developing frameworks to attend these issues (Fang et al 2020, Kassab et al 2020).

In conclusion, global access to the world-wide-web has changed scholarly communication forever. The discussion of research papers that was once restricted to the academic environment has moved onto scholarly social networking sites, making the information available for anyone interested to share and use. However, Altmetrics ought to be used as a complement of traditional metrics such as citation counts to assess research impact within the scholarly community and beyond. According to the Australian Research Council ${ }^{6}$, research impact is defined as "the demonstrable contribution that research makes to the economy, society, environment and culture beyond the contribution to academic research". Perhaps it is time that we begin assessing our journals based on other parameters besides the impact factor.

\section{REFERENCES}

Anonymous. 2018. Impact beyond citations. Nat Biomed Eng 2, 1.

Anonymous. 2019. Impact factor: No metric is perfect. Austral J Vet Sci 51, V.

Bai X, Lee I, Ning Z, Tolba A, Xia F. 2017. The role of positive and negative citations in scientific evaluation. IEEE Access 5, 17607-17617.

Bartneck C, Kokkelmans S. 2010. Detecting h-index manipulation through self-citation analysis. Scientometrics 87, 85-98.

Catalini C, Lacetera N, Oettl A. 2015. The incidence and role of negative citations in science. Proc Natl Acad Sci USA 112, 13823-13826.

6 Australian Research Council. 2017. Engagement and impact assessment pilot 2017: Report. https://libguides.library.usyd.edu.au/c. php?g=717256\&p=5270210; accessed February 10, 2020. 
Colquhoun D. 2003. Challenging the tyranny of impact factor. Nature $423,479$.

Delgado Lopez-Cozar E, Robinson-Garcia N, Torres-Salinas D. 2014. The Google Scholar Experiment: how to index false papers and manipulate bibliometric indicators. J Assoc Inf Sci Tech 65, 446-454.

Fang Z, Costas R, Tian W, Wang X, Wouters P. 2020. An extensive analysis of the presence of altmetric data for Web of Science publications across subject fields and research topics. Scientometrics 124, 2519-2549.

Fuentes J, Luque D, Lopez Gomez E. 2013. Bibliometric analysis of Spanish journals of education indexed in Journal Citation Report: Scientific production and controversial elements. Teor de la Edu 24, 183-217.

Hassona Y, Qutachi T, Dardas L, Alrashdan MS, Sawair F. 2019. The online attention to oral cancer research: An Altmetric analysis. Oral Dis 25, 1502-1510.

Kassab O, Bornmann, L, Haunschild, R. 2020. Can altmetrics reflect societal impact considerations?: Exploring the potential of altmetrics in the context of a sustainability science research center. Quant $S c i$ Stud 1, 792-809.

Knight CG, Kaye LK. 2016. 'To tweet or not to tweet?' A comparison of academics' and students' usage of Twitter in academic contexts. Innov Educ Teach Int 53, 145-155.

Krauskopf M, Krauskopf E, Mendez B. 2007. Low awareness of the link between science and innovation affects public policies in developing countries: The Chilean case. Scientometrics 72, 93-103.

Krauskopf E. 2013. Deceiving the research community through the manipulation of the impact factor. J Assoc Inf Sci Tech 64, 2403.

Krauskopf E, Garcia F, Funk RL. 2017. Bibliometric analysis of multi-language veterinary journals. TransInformação 29, 343-352.
Krauskopf E. 2018. A bibliometric analysis of the Journal of Infection and Public Health: 2008-2016. J Infect Public Health 11, 224-229.

Krauskopf E. 2020. Scholarly inbreeding in Latin American academically managed journals. High Learn Res Commun 10, 1-15.

Maflahi N, Thelwall M. 2018. How quickly do publications get read? The evolution of Mendeley reader counters for new articles. J Assoc Inf Sci Tech 69, 158-167.

McKiernan EC, Schimanski A, Nieves CM, Matthias L, Niles MT, Alperin JP. 2019 Use of the journal impact factor in academic review, promotion and tenure evaluations. eLife 8, e47338.

Pan R, Fortunato S. 2014. Author impact factor. Tracking the dynamics of individual scientific impact. Sci Rep 4, 4880.

Pang DSJ. 2019. Misconceptions surrounding the relationship between journal impact factor and citation distribution in veterinary medicine. Vet Anaesth Analg 46, 163-172.

Priem J, Groth P, Taraborelli D. 2012. The Altmetrics collection. PLoS One 7, e48753.

Pulverer B. 2013. Impact fact-or fiction, EMBO J 32, 1651e1652.

Sargent J, Matthews L. 2014. Latin American universities and technology commercialization. Lat Am Bus Rev 15, 167-190.

Thelwall M. 2017. Three practical field normalised alternative indicator formulae for research evaluation. J Infor 11, 128-151.

Van Eck NN, Waltman L. 2010. Software survey: VOSviewer, a computer program for bibliometric mapping. Scientometrics 84, 523-538.

Young AR, Mancuso N, Meeusen ENT, Bowles VM. 2000. Characterization of proteases involved in egg hatching of the sheep blowfly, Lucilia cuprina. Int J Parasitol 30, 925-932.

Zahedi Z, Costas R, Wouters P. 2014. How well developed are altmetrics? A cross-disciplinary analysis of the presence of 'alternative metrics' in scientific publications. Scientometrics 101, 1491-1513. 
